\title{
Joffre Dumazedier e o Centro de Estudos do Lazer do Sesc São Paulo
}

\author{
Joffre Dumazedier and the Leisure Study Center of Sesc São Paulo \\ Joffre Dumazedier y el Centro de Estudio de Ocio Sesc São Paulo \\ Regiane Galante ${ }^{1}$; Silvia Cristina Franco AMARal ${ }^{2}$ \\ SERVIÇo Social do COMÉrcio, SESC, São Carlos-SP, BraSil \\ Universidade ESTADUal DE CAMPINAS, UNICAMP, CAMPINAS-SP, BRaSIL
}

\begin{abstract}
RESUMO
Este artigo apresenta o contexto da criação do Centro de Estudos do Lazer do Sesc São Paulo - CELAZER - e sua dinâmica de funcionamento, destacando a presença do sociólogo francês Joffre Dumazedier, contratado para sistematizar e fundamentar teoricamente as ações da instituição no campo do lazer, bem como ampliar a formação e a capacitação técnica dos seus funcionários. Traz, ainda, informações a respeito do trabalho realizado pelo pesquisador e apresenta o legado deixado por ele em relação à produção e a disseminação do conhecimento sobre a temática no Brasil. Conclui-se que além das pesquisas e publicações realizadas, o CELAZER contribuiu na constituição do pensamento sobre lazer no país e na propagação do conhecimento advindo de Dumazedier, que inclui o desenvolvimento dos chamados Conteúdos Culturais do Lazer, que foi disseminado no quadro técnico do Sesc e, posteriormente, ampliado para as Universidades por meio dos técnicos e pesquisadores que seguiram suas carreiras acadêmicas.
\end{abstract}

Palavras-chave: Lazer. CELAZER. Joffre Dumazedier.

\begin{abstract}
This article presents the context of the creation of the Sesc São Paulo Center for Leisure Studies - CELAZER and its working dynamics, highlighting the presence of the French sociologist Joffre Dumazedier, hired to systematize and theoretically support the institution's actions in the field of leisure, as well as expanding the training and technical qualification of its employees. It also brings information about the work carried out by the researcher and presents the legacy left by him in relation to the production and dissemination of knowledge on the subject in Brazil. It is concluded that, in addition to the research and publications carried out, CELAZER contributed to the constitution of thought about leisure in the country and to the dissemination of knowledge arising from Dumazedier, which includes the development of the so-called Cultural Contents of Leisure, which was disseminated in the technical framework of Sesc and, later, expanded to Universities through technicians and researchers who followed their academic careers.
\end{abstract}

Keywords: Leisure. CELAZER. Joffre Dumazedier.

\section{RESUMEN}

Este artículo presenta el contexto de la creación del Centro de Estudios del Ocio Sesc São Paulo - CELAZER - y su dinámica de trabajo, destacando la presencia del sociólogo francés Joffre Dumazedier, contratado para sistematizar y apoyar teóricamente las acciones de la institución en el campo del ocio, así como ampliar la formación y calificación técnica de sus empleados. También trae información sobre el trabajo realizado por el investigador y presenta el legado que dejó en relación a la producción y difusión del conocimiento sobre el tema en Brasil. Se concluye que, además de las investigaciones y publicaciones realizadas, CELAZER contribuyó a la constitución del pensamiento sobre el ocio en el país y a la difusión del conocimiento surgido de Dumazedier, que incluye el desarrollo de los denominados Contenidos Culturales del Ocio, que se difundió en el marco técnico del Sesc y, posteriormente, se expandió a las Universidades a través de técnicos e investigadores que siguieron sus carreras académicas.

Palabras clave: Ocio. CELAZER. Joffre Dumazedier.

\footnotetext{
1 Gerente Adjunto na unidade Sesc São Carlos. E-mail: regiane.galante@ sescsp.org.br. ORCID: https://orcid.org/0000-0001-8194-9960.

${ }^{2}$ Docente MS5.2 da Faculdade de Educação Física, Departamento de Educação Física e Humanidades da Unicamp. E-mail: scfa@ fef.unicamp.br. ORCID: https://orcid.org/0000-0001-7708-7034.
} 


\section{INTRODUÇÃO}

Este artigo $^{3}$ apresenta a narrativa da fundação e atuação do Centro de Estudos do Lazer do Sesc São Paulo - CELAZER, que no período de 1978 a 1983, fortemente influenciado pelo pensamento do sociólogo francês Joffre Dumazedier, contribuiu efetivamente com a produção e a disseminação do conhecimento sobre a temática no Brasil, por meio de suas publicações, pela organização de cursos e seminários e pela realização de pesquisas sobre o tema. Traz, ainda, informações a respeito da presença, método e legado deixado por Joffre Dumazedier durante o período no qual atuou como consultor do CELAZER e do Sesc São Paulo.

De caráter qualitativo, a pesquisa explorou o acervo do Sesc Memórias - o Centro de Memória do Sesc São Paulo - e todo o material produzido pelo CELAZER, além dos documentos que comprovam sua criação e atuação, a fim de compreender o contexto no qual o Centro foi criado e também seu funcionamento. Além disso, com inspiração na História Oral e nos Estudos da Memória, foram realizadas entrevistas semiestruturadas com participantes do CELAZER, para identificar suas atuações e contribuições na produção de conhecimento sobre lazer no período, assim como a presença e a relação deste grupo de pesquisadores com seu orientador, Joffre Dumazedier.

Fizeram parte da pesquisa: o professor Luiz Octávio de Lima Camargo, coordenador do CELAZER à época, Mário Daminelli e Dante Silvestre Neto, identificados como orientadores sociais/pesquisadores/autores mais importantes do centro ${ }^{4}$. Nas entrevistas iniciais, outros nomes foram revelados e posteriormente confirmados pelos documentos impressos, dos quais apenas aqueles citados repetidamente pelos três entrevistados principais passaram a integrar o grupo de entrevistados: Sérgio José Batistelli, Antonio Carlos Moraes Prado, Erivelto Busto Garcia e Newton Cunha ${ }^{5}$.

Assim, o presente texto foi construído a partir dos documentos impressos disponíveis no Sesc Memórias, referências bibliográficas e pesquisas anteriores permeadas pelos discursos dos entrevistados.

\section{PERCURSO HISTÓRICO DA CRIAÇÃo do CELAZER}

Para situar historicamente o CELAZER no Sesc São Paulo, faz-se necessário retornar a meados da década de 1940, mais precisamente ao ano de 1946, quando foi criado o Serviço Social do Comércio - Sesc, "[...] com a finalidade de planejar e executar medidas que contribuam para o bem-estar e melhoria do padrão de vida dos comerciários e suas famílias e, bem assim, para o aperfeiçoamento moral e cívico da coletividade” (SESC SP, 1996, p. 12).

\footnotetext{
${ }^{3} \mathrm{O}$ texto é parte da Tese de Doutorado intitulada Memórias do Celazer: influências e contribuições para os estudos do lazer no Brasil, defendida em 2018 na Faculdade de Educação Física da Unicamp.

${ }^{4}$ Um quarto autor/pesquisador, o Professor Paulo de Salles Oliveira também foi identificado como um dos participantes mais importantes do CELAZER. Contudo, não aceitou participar da pesquisa/conceder entrevista alegando motivos pessoais.

${ }^{5}$ Dois importantes nomes nos estudos do lazer também foram funcionários do Sesc na década de 1970, mas não fizeram parte do CELAZER e nem mesmo colaboraram nas atividades do Centro - Antonio Carlos Bramante e Nelson Carvalho Marcellino. O Professor Bramante saiu do Sesc antes da criação do CELAZER, e o Professor Marcellino dedicou-se amplamente ao trabalho das UNIMOS e à Ação Comunitária no período de 1975 a 1983 , deixando o Sesc para seguir carreira acadêmica, não havendo registros de sua participação ou colaboração com o CELAZER nos documentos pesquisados ou nos relatos dos entrevistados.
} 
Naquele momento, o Brasil passava por um período de grande crescimento industrial estimulado, sobretudo, pelo regime do Estado Novo ${ }^{6}$, também marcado pelo aumento das preocupações do Estado com a política social (BICKEL, 2013). Com o êxodo rural causado pela esperança de vagas no mercado de trabalho devido à instalação das grandes indústrias nas cidades, surgem sérios problemas decorrentes da falta de condições de acolher a todos: pouca disponibilidade de moradias, falta de saneamento básico, ausência de escolas e transporte público, atendimento precário à saúde e dificuldades mesmo para com "[...] o tão sonhado emprego" (ARANHA, 1989, p. 252). Além disso, com a aprovação da Consolidação das Leis do Trabalho, a CLT, em 1943, ampliavam-se os movimentos operários e sindicais e o controle do Estado sobre a relação capital e trabalho (JAMBEIRO et al., 2004).

Nesse contexto social e econômico, eram latentes as tensões entre empregados e empregadores. Todo esse cenário fez com que a classe empresarial se mobilizasse a fim de definir qual seria sua atuação frente ao quadro que se apresentava e colocava em risco o tão esperado desenvolvimento nacional estimulado pelo Estado. Assim, foi realizada em maio de 1945 a primeira Conferência das Classes Produtoras - I Conclap, na cidade de Teresópolis/RJ, cujos debates resultaram numa carta de intenções do empresariado, a chamada Carta da Paz Social, que trazia "[...] recomendações propostas pelos empresários e definiam basicamente uma postura de justiça social, capaz de assegurar aos trabalhadores melhores condições de vida" (DIAS, 2013, p. 32).

\begin{abstract}
É um documento altamente expressivo do espírito de solidariedade e do realismo amadurecido dos homens de empresa brasileiros desta geração. Ela deverá contribuir para harmonizar e pacificar o capital e o trabalho em nosso país, em um plano superior de entendimento recíproco. Com ela, nos apresentamos ante os empregados, convidando-os a fundar, sobre base sólida, uma política de mútua compreensão e de respeito recíproco ${ }^{7}$ (SESC, 2012, p. 9).
\end{abstract}

Levando em conta as intenções colocadas na Carta da Paz Social, em 1946, o então Presidente da República Eurico Gaspar Dutra assinou o decreto lei $\mathrm{n}^{\circ}$ 9853, cujo artigo $1^{\circ}$ atribuía à Confederação Nacional do Comércio, presidida por João Daudt D'Oliveira, a tarefa de "[...] criar o Serviço Social do Comércio - Sesc" (SESC SP, 1996, p. 12), marcando definitivamente uma nova forma de promoção, pelas classes patronais, da assistência social e da qualificação dos trabalhadores.

Desde a sua criação, a finalidade do Sesc era o planejamento e a execução de ações que contribuíssem para o bem-estar e a melhoria da qualidade de vida dos trabalhadores no comércio de bens, serviços e turismo, de suas famílias e da comunidade em geral. Em São Paulo, o primeiro Conselho Regional, assessorado por um grupo de consultores de diversos segmentos da sociedade - líderes sindicais, médicos, engenheiros etc. - estabeleceu as atividades prioritárias: os esforços institucionais se voltariam à assistência ao comerciário e sua família, principalmente nos setores médico, odontológico, sanitário e hospitalar, por meio da oferta desses serviços a custos reduzidos.

Como entidade de assistência social, o Sesc desenvolvia um trabalho complementar àquele das agências governamentais no campo da prestação de serviços sociais, em especial

\footnotetext{
${ }^{6}$ É chamado de Estado Novo o período ditatorial que vai de 1937 a 1945, quando Getúlio Vargas, apoiado principalmente pelos militares, tomou o poder e permaneceu como Presidente da República, instaurando uma nova Constituição Federal (Constituição de 1937). O Estado Novo marcou a vida política e administrativa brasileiras, com a supressão de direitos políticos e o fechamento do Congresso Nacional, das Assembleias Legislativas e das Câmaras Municipais. Contudo, no período também ocorreu "[...] o crescimento da urbanização, o desenvolvimento industrial e o florescimento de uma produção cultural nacional" (ALMEIDA; GUTIERREZ, 2011, p. 137).

${ }^{7}$ Excerto do discurso pronunciado por João Daut d'Oliveira, por ocasião da posse da diretoria da Confederação Nacional do Comércio, em janeiro de 1946, no qual se refere à Carta da Paz Social (SESC, 2012, p. 9).
} 
nas áreas da saúde e alimentação. Assim foram implantadas as primeiras unidades na capital paulista, especializadas neste tipo de atuação: o Restaurante do Comerciário, na rua Riachuelo, que fornecia alimentação para os comerciários do centro a preços reduzidos, e a Clínica Central de Serviços Especializados, na rua Florêncio de Abreu, ambos inaugurados em 1947.

O leque de serviços era amplo, assim como os anseios da classe trabalhadora no comércio. Desta forma, já nos primeiros anos a ação da entidade foi-se diversificando e passou a abranger áreas de interesses mais amplos, inclusive com a instalação dos primeiros Centros Sociais ${ }^{8}$, casas muitas vezes modestas, mas localizadas estrategicamente em bairros importantes da capital paulista, como Tatuapé, Bela Vista, Santana e Água Branca, e também em algumas cidades do interior, como Campinas e Santos (SESC SP, 2013).

Na década de 1950, o Sesc já desenvolvia ações em vários estados, principalmente por meio da instalação das Colônias de Férias voltadas ao descanso do trabalhador. Foram instaladas colônias em Bertioga/SP, Caucaia/CE, Petrópolis e Macaé/RJ, Salvador/BA, Belo Horizonte/MG, Matinhos/PR e Garanhuns/PE (SESC, 1972).

O período de expansão do trabalho do Sesc também corresponde a um momento de franco desenvolvimento para o país, principalmente entre os anos de 1955 e 1960, no governo Juscelino Kubitscheck, cujo Programa de Metas foi um projeto de dotação de infraestrutura básica, ou seja, de grande industrialização, modificando os rumos da economia brasileira no contexto internacional.

Neste mesmo período, nos Centros Sociais da capital paulista, além dos trabalhos que inicialmente eram voltados ao atendimento das necessidades na área de saúde, aconteciam cursos de inglês, português, corte e costura e balé infantil, e nos anos que se seguiram nasceram grupos de teatro, música, dança, cinema, fotografia, artes plásticas e os grêmios e clubes de funcionários de empresas comerciais (GALANTE, 2006; SESC SP, 2013).

Esse processo levou a reflexões teóricas e técnicas quanto ao tipo de serviço social a ser desenvolvido pela entidade, resultando em propostas de diversificação e ampliação da ação institucional nas cidades nas quais não havia um Centro Social instalado. Assim, sob a perspectiva de disseminar o trabalho a e missão da instituição no interior do estado, o Sesc São Paulo inaugura seu trabalho de Ação Comunitária com as Unidades Móveis de Orientação Social, as UNIMOS, na década de 1960.

Figura 1: Veraneio da UNIMOS - Unidade Móvel de Orientação Social.

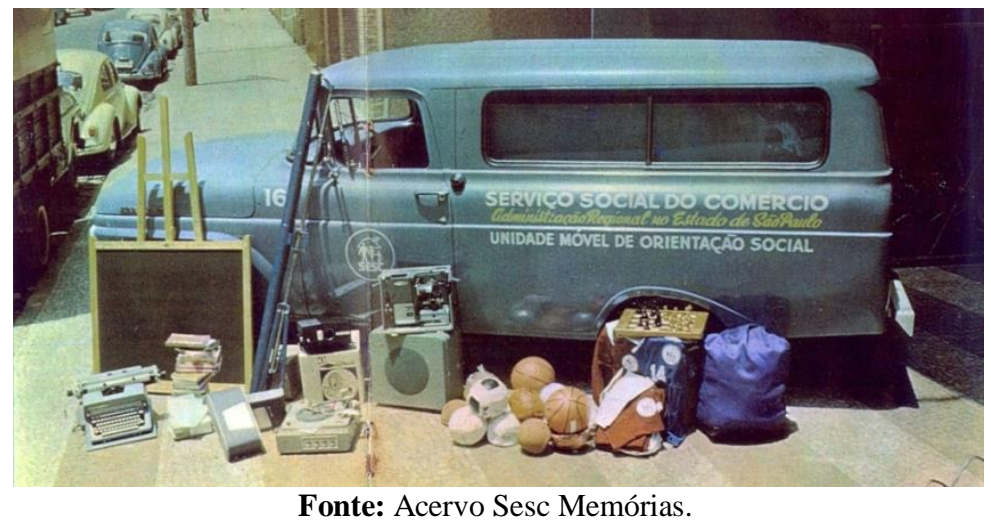

\footnotetext{
${ }^{8}$ Os Centros Sociais eram os espaços/imóveis que o Sesc instalava, para se tornarem locais "físicos" de referência para os trabalhadores no comércio, nos quais era possível se cadastrar na entidade para usufruir dos serviços prestados, tais como reservar uma hospedagem na Colônia de Férias em Bertioga, ou se inscrever e participar de algum curso ou oficina, além de se tornarem espaços de convivência e de encontro de grupos diversificados.
} 
Organizada em um furgão/veraneio, com dois ou três Orientadores Sociais ${ }^{9}$, alguns materiais esportivos, máquina de escrever, projetor de filmes $16 \mathrm{~mm}$, aparelho de som/vitrola e outros equipamentos, as UNIMOS instalava-se em praças, parques e até mesmo em salões paroquiais e, nestes espaços, eram realizadas atividades de lazer e recreação para a comunidade, incluindo a organização de torneios esportivos, jogos de mesa como xadrez e carteado, exibições de cinema, concursos de beleza, palestras, oficinas de artes manuais etc., além da mobilização de lideranças locais e voluntários para darem continuidade aos trabalhos por conta própria (DIAS, 2013; GALANTE, 2006).

Um desses orientadores era o sociólogo Renato Antonio Quadros de Souza Requixa ${ }^{10}$, que havia sido contratado em 1953 para atuar no Centro Social Florêncio de Abreu e, posteriormente, e passou a compor a equipe das UNIMOS na década de 1960.

Eu estava assim muito entusiasmado com o Direito, e comecei a trabalhar no Serviço Social do Comércio, o Sesc, quando então comecei a me envolver com a área de recreação. [...] foi um trabalho que nós até chamávamos de ação comunitária. As pessoas eram interessadas em assumir certos problemas que tinham na comunidade, ativados por nós, os orientadores sociais. Faziam com que as próprias lideranças públicas que surgiam, elas tomassem consciência dos problemas, às vezes até problemas menores, que elas próprias poderiam solucionar (Entrevista com Renato Requixa - GOMES, C. L., 2004, p. 4).

Nas incursões das UNIMOS pelo estado de São Paulo, as intervenções nas cidades eram realizadas em parceria com órgãos públicos, como prefeituras ou igrejas, e sempre com a apresentação do Sindicato do Comércio Varejista ${ }^{11}$ local

[...] fomos a cidades médias, depois fomos a cidades menores, e sempre marcado pela apresentação do presidente do sindicato local. O Sindicato do Comércio Varejista local. Então esse presidente de sindicato nos abria as portas da cidade. Então aí não, eles nos tranquilizavam, nos apoiavam e a gente desenvolvia trabalhos de educação física, também de artes e estudos sociais (Entrevista com Renato Requixa-GOMES, C. L., 2004, p. 4).

No período de atuação das UNIMOS - que compreende as décadas de 1960 e 1970 -, a instituição assume fortemente o lazer como possibilidade de trabalho social e amplia seu quadro de orientadores, mas ainda não demonstra preocupação em relação ao aprimoramento teórico-conceitual sobre o lazer em si. Além disso, esse mesmo período de intervenção das UNIMOS nas cidades corresponde a um período importante na conjuntura política brasileira

Esse grupo de orientadores sociais que foi prestigiado. Era muito importante na época, então trabalhou muito: trabalhou assim, com vontade para a redemocratização do país, com Juscelino Kubitscheck e essas coisas todas. O PSB, que era o grande partido na época, o presidente, ele era amigo do Juscelino, então, foi uma época muito gostosa, muito bonita, e depois surgiu a famosa revolução de (19)64 (Entrevista com Renato Requixa - GOMES, C. L., 2004, p. 4).

A Revolução a que se refere Renato Requixa foi o Golpe Civil-Militar de 1964. Conforme aponta Ghiraldelli Junior (2006), falava-se em Revolução, mas não se tratou de

\footnotetext{
${ }^{9}$ Orientador Social era o nome do cargo no qual os profissionais eram contratados pelo Sesc para ministrar as atividades e fazer a interlocução com a comunidade, fosse num Centro Social ou mesmo nas UNIMOS. Eram, em geral, cientistas sociais, assistentes sociais, professores de educação física ou pedagogos.

${ }^{10}$ Renato Requixa infelizmente faleceu no decorrer da pesquisa de doutorado que originou este artigo.

${ }^{11}$ Os Sindicatos do Comércio Varejista são os órgãos que mantêm e administram o Sesc. Os presidentes dos Sindicatos são eleitos pelos seus pares para a função de Conselheiros no Conselho Regional de cada estado.
} 
“[...] uma revolução propriamente dita e, sim, de golpe militar" (GHIRALDELLI JUNIOR, 2006, p. 105), momento da história nacional marcado pela repressão, pela censura, pela perda do poder de participação e crítica da população, e ainda por repressões violentas a qualquer oposição ao regime.

De acordo com Laniado (2014), o regime militar criou "[...] uma política regressiva e essencialmente não democrática" (LANIADO, 2014, p. 37). Por meio da reestruturação institucional e da ordem jurídica, o autoritarismo do Estado e a concentração do poder nas mãos das Forças Armadas ocasionaram o enfraquecimento da participação civil nas diretrizes econômicas e políticas brasileiras.

O período ditatorial iniciado em 1964 durou vinte e um anos, e serviu de palco para o revezamento de cinco generais na Presidência da República. Além disso, a política econômica continuou optando pelo aproveitamento do capital estrangeiro (GHIRALDELLI JUNIOR, 2006), e gerou um modelo que concentrava a renda numa pequena parcela da população e submetia a maior parte dos trabalhadores ao arrocho salarial ${ }^{12}$. A abertura ao capital internacional, a instalação de multinacionais e o grande desenvolvimento industrial marcaram este período, conhecido como Milagre Econômico ${ }^{13}$.

Neste contexto de Ditadura, e sob a proposta desenvolvimentista pautada na indústria, foram elevadas as jornadas de trabalho e, em algumas ocasiões, "[...] chegou-se a ultrapassar o limite de quarenta e oito horas semanais de trabalho e as horas extras foram inúmeras vezes convertidas em horas ordinárias" (SANT'ANNA, 1994, p. 27).

Em contrapartida, é possível verificar um aumento significativo das discussões sobre lazer, embora o tempo livre dos trabalhadores tenha diminuído consideravelmente, situação que, atrelada ao já citado arrocho salarial, obrigava os trabalhadores a buscarem outras ocupações para completar seus rendimentos.

O que Sant'Anna (1994) pontua a esse respeito é que

A primeira impressão que temos ao lançar nossas atenções sobre esta época é a de que vivíamos simultaneamente dois movimentos distintos e opostos: por um lado, a exaltação a uma série de conteúdos do tempo livre permeados de ludicidade e, por outro, a ênfase no trabalho preconizada pelo Governo Militar e fortalecida pela política do "Milagre Econômico", que contribuiu para reduzir drasticamente o tempo livre da maior parte dos assalariados. Assim, poder-se-ia imaginar que a exaltação a determinados usos do tempo livre, a recomendação e a legitimação de certas atividades e espaços de diversão consistiam num lado a salvo do rosto pálido da ditadura militar. [...] percebeu-se que a preocupação com as questões do tempo livre, principalmente na cidade de São Paulo, não emergiu de posições descompromissadas com a manutenção dos valores econômicos vigentes, nem foi implementada em função de interesses contrários ao desenvolvimento da política institucional dominante (SANT'ANNA, 1994, p. 9).

Corroborando com tais apontamentos, Marcassa (2009) considera que neste momento se iniciou no Brasil "[...] uma preocupação com o lazer e um movimento de inspeção dos usos do tempo livre do trabalhador, especialmente nos grandes centros urbanos" (MARCASSA, 2009, p. 248).

Nesse período o lazer passa, de acordo com Sant'Anna (1994), a ser amplamente utilizado para designar os usos do tempo livre que, de algum modo, pudessem ser úteis

\footnotetext{
${ }^{12}$ Arrocho salarial é a consequência de uma política salarial cujos reajustes não acompanham a inflação, ocasionando a diminuição do poder de compra dos trabalhadores, por consequência aumentando o endividamento e piorando as condições de vida da população.

13 "Expressão atribuída à política econômica empreendida pelo então Ministro da Fazenda Delfim Neto na década de 1970, na qual se fez acreditar que o Brasil estava tendo grande desenvolvimento" (GONÇALVES JUNIOR, 2002, p. 35).
} 
economicamente e aceitos pelos padrões e valores morais instituídos. Intervenções institucionais das mais diversas naturezas colaboraram para a retificação desse conceito, visando tornar as práticas lúdicas, de alguma maneira, úteis e valorosas aos bons costumes. Nesta mesma linha de raciocínio, Brunhs (1997) observa que desde o início das discussões a respeito do lazer, o que se nota é uma visão funcionalista, posicionando o homem em função do sistema vigente, buscando uma manutenção da ordem social presente.

Com o inevitável aumento do chamado tempo livre, políticos e empresários se preocuparam com os usos que os trabalhadores poderiam fazer de suas horas de folga, sendo grande o receio de que elas fossem empregadas com atividades que pudessem degradar moralmente a sociedade. Ao invés de se entregarem ao alcoolismo, aos jogos de azar, ao ócio e a outros vícios, os trabalhadores deveriam fazer 'bom uso' do tempo liberado do trabalho, ocupando-o com atividades consideradas saudáveis, educativas e socialmente úteis (GOMES, 2003, p. 80).

Voltemos, contudo, ao ano de 1964. Naquele momento, o Sesc elaborava seu Regulamento e o Plano Geral de Ação, não sem a preocupação de “[...] produzir respostas precisas aos anseios de seus dirigentes, em vista das demandas da nova ordem econômica e política sobre a qual o país começava a tomar ciência” (BICKEL, 2013, p. 67). Em São Paulo, Renato Requixa é convidado pelo então Presidente da Federação do Comércio Varejista, Dr. Brasílio Machado Neto, a ser diretor das UNIMOS no estado de São Paulo.

Em relação ao trabalho das Unidades Móveis, neste período

[...] nós sentimos que as autoridades locais começaram a nos temer, assim, como se nós fôssemos não uns animadores culturais, mas uns agitadores. E a coisa começou a ficar meio difícil pra nós. Tanto que, no último ano, nós estávamos atendendo umas duzentas cidades e então algumas autoridades chegaram a prender alguns orientadores sociais nossos, apesar de serem funcionários de uma entidade patronal. Você vê como a revolução foi forte naquele momento (Entrevista com Renato Requixa-GOMES, C. L., 2004, p. 4).

Durante o tempo que se dedicou a coordenar o trabalho das UNIMOS, Renato Requixa recebeu, de um de seus assistentes ${ }^{14}$ que havia viajado à Suécia para fazer uma pesquisa sobre sociologia do trabalho, uma revista com um artigo assinado por Joffre Dumazedier:

E depois, mesmo em (19)64, um assistente meu pediu uma licença do Sesc e foi para a Suécia fazer um trabalho, um estudo sobre sociologia do trabalho [...]. Então ele me mandou de lá um livro, aliás uma revista de sociologia onde havia um artigo do Joffre Dumazedier sobre o lazer, a importância do lazer. Quando eu li aquilo eu disse: ai meu Deus, era aquilo que a gente estava fazendo [...]. Mas aí, eu, curioso a respeito do assunto, comecei a ler, a procurar, viajei pra Europa, procurei material sobre lazer [...] (Entrevista com Renato Requixa - GOMES, C. L., 2004, p. 5).

Entusiasmado com o tema, Requixa procurou aprofundar seus estudos e tornou-se um conhecedor das propostas e teorias de Joffre Dumazedier, encontrando nos trabalhos do sociólogo francês o respaldo teórico necessário para desenvolver a ação institucional nas UNIMOS.

Mas foi em 1969 que um evento considerado um marco na história dos estudos do lazer no Brasil: o "Seminário sobre Lazer: Perspectivas para uma cidade que trabalha", realizado pelo Sesc São Paulo, em conjunto com a Secretaria Municipal do Bem Estar Social, deflagra novas discussões e perspectivas sobre a temática

\footnotetext{
${ }^{14} \mathrm{O}$ assistente de Requixa era Otto Celso Domingues, que estava na Suécia estudando Sociologia do Trabalho pelo Sesc, conhece as teorias de Joffre Dumazedier e encaminha a Requixa o material.
} 
Em 1969, o Sesc de São Paulo e a Secretaria de Bem-estar do Município resolveram empreender um evento público para discussão do tema, um seminário de estudos aproximando universidade, planejadores e trabalhadores sociais [...]. A repercussão do Seminário [...] foi perto de catastrófica. [...] De um lado, a favor do tema, devem ser lembrados o Sesc e alguns setores públicos minoritários, sobretudo de urbanistas, que não se conformavam com a degradação dos espaços urbanos e com a morte do centro histórico. Havia, também, os professores de educação física e os recreadores escolares, que se sentiam marginalizados em face da tônica dominante na escola. De outro, contrários, havia os empresários, os 'donos' do trabalho, em parceria inusitada com a sociologia estabelecida, sobretudo da USP e da PUC, sem deixar de mencionar a parcela majoritária de assistentes sociais e profissionais que se dedicavam ao cuidado das populações carentes (CAMARGO, 2003, p. 36-37).

Vários autores (SANT'ANNA, 1994; MARCASSA, 2002; PEIXOTO; PEREIRA, 2009; CAMARGO, 2003; WERNECK, 2003) relatam a dinâmica estabelecida nas discussões, entre as correntes favoráveis e contrárias à existência do lazer enquanto campo teórico e sua consideração como algo prioritário na vida social durante o referido evento. Nos debates, cada grupo defendeu suas opiniões e posições - contrárias ou a favor - da necessidade da garantia do lazer ao trabalhador, inclusive frente a outros aspectos, como trabalho, urbanização, desemprego, pobreza, e sempre à sombra do Regime Militar que presidia o Brasil na época.

\begin{abstract}
Os argumentos favoráveis eram bastante tímidos [...]. As justificativas ao estudo do lazer, assim, eram apenas as instrumentais, aquelas que solicitavam que se passasse do primeiro ao segundo estágio na preocupação com o lazer, que se pensasse no lazer como solução para encaminhamento de outros problemas. Como viver apenas de trabalho? Como descansar, se não há lazer? Como lidar com populações carentes, a não ser através de atividades lúdicas? Já os argumentos contrários não eram nada tímidos. Refugiavam-se, às vezes, à sombra de bandeiras inatacáveis na época. Era o caso da primeira objeção que afrontava o tema do lazer como desviacionista dos graves problemas da nossa sociedade de então, como a tortura de opositores ao regime, a fome, o desemprego, etc. Era um argumento difícil de refutar [...]. Curiosamente, outros assuntos eram livremente discutidos como o da urbanização, dos transportes, da saúde, da própria poluição, que incluíam ou deveriam incluir o lazer, mas o tema diretamente colocado do lazer parecia afrontar algo (CAMARGO, 2003, p. 37).
\end{abstract}

A repercussão do Seminário acabou por motivar profissionais ligados aos estudos e à intervenção no campo do lazer a intensificarem as buscas por uma melhor fundamentação para o tema (GOMES, C. L., 2008), impulsionando os estudos do lazer no Brasil.

Também motivado pelo Seminário, Renato Requixa publica em formato de livreto a Conferência de Abertura "As Dimensões do Lazer", proferida por ele e cuja repercussão extrapolou, segundo Requixa, as discussões no próprio evento.

Eu abri o Congresso com uma palestra chamada As dimensões do lazer. Aí o lazer nessa palestra, o lazer entrou nos jornais. A palavra lazer entrou nos jornais. Não existia isso em 1969 [...] então foi o primeiro congresso que saiu, e a primeira vez que se falou em lazer no Brasil (Entrevista com Renato Requixa - GOMES, C. L., 2004, p. 9).

Renato Requixa busca, também a partir do Seminário, uma aproximação com o próprio Dumazedier, vislumbrando futuras possibilidades no desenvolvimento do trabalho da instituição no campo do lazer

Em seguida eu estive na França com o Dumazedier, levei a minha publicação pra ele, todo orgulhoso, lógico, tinha um trabalho sobre lazer [...]. E ele me mandou uma 
carta. Ele leu, gostou, se interessou muito pela coisa (Entrevista com Renato Requixa-GOMES, C. L., 2004, p. 9).

Favorável às ideias de Dumazedier, o Sesc São Paulo assumiu nas suas atividades o entendimento do lazer enquanto vivência ligada ao tempo livre, "[...] que é limitado pelo tempo de trabalho profissional, pela duração do tempo consagrado a outras atividades improdutivas, pelo tempo destinado às obrigações domésticas e familiares" (DUMAZEDIER, 1974), entendimento logo incorporado pelo Departamento Nacional e difundido para todos os departamentos regionais.

[...] e o diretor-geral do Sesc no Brasil, que era o Moacir Lopes Meirelles, ele também começou a se interessar e disse 'Ah não, então vamos fazer um seminário nacional! Vocês fizeram um seminário em São Paulo, então vamos fazer um seminário nacional'. Eu disse 'vamos, mas precisamos chamar um bam bam bam internacional chamado Dumazedier'. Aí eu estive em Paris e eu convidei o Dumazedier. Ele veio fazer a palestra inicial [...](Entrevista com Renato Requixa GOMES, C. L., 2004, p. 5).

Esse seminário se concretiza no ano de 1975 , no período de 24 a 29 de agosto, no $1^{o}$. Encontro Nacional sobre Lazer - Cultura, Recreação e Educação Física, que foi realizado pelo Departamento Nacional do Sesc, com o apoio da Fundação Van Clé ${ }^{15}$ e da Organização das Nações Unidas para a Educação, a Ciência e a Cultura - UNESCO, em parceria com o Serviço Social da Indústria - Sesi e com o patrocínio do Ministério do Trabalho (SESC, 1977), e do qual participaram técnicos do Sesc de todos os Departamentos Regionais. No evento, Dumazedier proferiu a conferência de abertura intitulada Lazer nas sociedades em desenvolvimento (BICKEL, 2013, p. 136).

No ano seguinte, quando do falecimento do Dr. Brasílio Machado Neto e da eleição de José Papa Junior ao cargo de Presidente da Federação do Comércio do estado de São Paulo, Requixa torna-se Diretor do Departamento Regional do Sesc São Paulo e, dois anos depois de assumir a Diretoria Regional, cria o CELAZER.

E eu fui convidado para assumir todo o regional do Sesc São Paulo e obviamente eu ia insistir na temática do lazer em São Paulo. Então aí eu consegui, com o Regional, criar um centro de estudos sobre lazer, o CELAZER. E sempre preocupado em fazer com que as pessoas estudassem lazer, se desenvolvessem (Entrevista com Renato Requixa-GOMES, C. L., 2004, p. 8).

Considerando sua aproximação com os estudos do lazer propostos por Joffre Dumazedier, o CELAZER o contrata como consultor para orientar os trabalhos e pesquisas do Centro, bem como a atuação do Sesc São Paulo nas áreas de lazer e recreação.

\section{DUMAZEDIER NO CELAZER}

A presença de Joffre Dumazedier e seu pensamento sobre lazer no Brasil antecede o convite realizado por Renato Requixa e pelo Sesc. Outras instituições e movimentos sociais brasileiros tiveram contato com a produção do sociólogo francês, e também contaram com suas orientações em estudos e pesquisas mesmo antes da participação naquele $1^{o}$. Encontro

\footnotetext{
${ }^{15}$ A Fundação Van Clé foi fundada em 1968, em Bruxelas/Bélgica, em homenagem ao padre Antoon Van Clé, e seus objetivos eram contribuir para a humanização dos lazeres, promover a pesquisa científica no domínio do lazer, e auxiliar a realização de projetos que têm por fim melhorar a qualidade vida das pessoas (SESC, 1977, p. 26)
} 
Nacional sobre Lazer - Cultura, Recreação e Educação Física, que foi realizado pelo Departamento Nacional do Sesc, em 1975.

De acordo com registros encontrados nos estudos de diferentes autores (RODRIGUES, 2010, MARCASSA, 2009; GOMES, C. M., 2008; SESC, 1977), a primeira vez que o sociólogo esteve em atividades no país foi no período de 1961-1963, a convite do Ministério do Trabalho e Previdência, da Universidade de Brasília, do MCP - Movimento de Cultura Popular no Recife e das autoridades eclesiais do estado de Pernambuco, cuja presença visava contribuir com as ações desenvolvidas no âmbito da Educação Social e Comunitária e da Cultura Popular da região nordeste.

[...] participa também do I Encontro Nacional de Alfabetização e Cultura Popular realizado em Recife em setembro de 1963, oportunidade na qual os militantes dos vários movimentos de educação e cultura popular puderam tomar contato com as produções e discussões sobre educação popular, cultura popular e animação então vigentes na França (MARCASSA, 2009, p. 162-163).

Outra organização que se aproximou do pensamento de Joffre Dumazedier, inclusive publicando livros e realizando eventos com sua participação foi o Centro de Estudos de Lazer e Recreação (CELAR) na PUC-RS. Junto ao CELAR, Dumazedier ministrou, em setembro de 1975, um curso para alunos e professores com o tema Teoria do Lazer. Em seguida, o discurso do pesquisador foi transcrito e publicado, sob o título Questionamento Teórico do Lazer (DUMAZEDIER, 1975), sob coordenação de Lúcia Castillo. Em setembro de 1976, Dumazedier realiza o curso Sociologia de Autoformação e, em 1977, ministrou o curso $O$ Lazer e os problemas da autoformação (JOÃO; CLEMENTE, 1997).

Entretanto, embora várias instituições brasileiras tenham se apropriado do entendimento de lazer de Dumazedier e ajudado a reverberar suas ideias, conforme apontam alguns estudos (MARCASSA, 2009, GOMES; MELO, 2003, SANT'ANNA, 1994) foi por meio do Sesc São Paulo que Joffre Dumazedier disseminou de maneira mais ampla suas propostas no Brasil.

A partir de 1975, época da realização do Primeiro Encontro Nacional do Lazer, realizado no Rio de Janeiro, o contato de Dumazedier com o Sesc de São Paulo passou a ser cada vez mais intenso. [...] Esse período, que se estendeu por toda a década de (19)70, contou com o desenvolvimento de inúmeros estudos sobre o lazer na capital paulista, grandemente influenciados pelos estudos realizados por técnicos do Sesc (SANT'ANNA, 1994, p. 49).

A partir desta primeira vinda de Dumazedier, mediada pelo então Diretor Regional do Sesc São Paulo Renato Requixa, criou-se um profundo e duradouro vínculo entre a Instituição e o sociólogo.

Nos anos seguintes, muitas foram as vezes que Dumazedier esteve no Brasil mediando as atividades do CELAZER, como consultor dos estudos do Centro, conforme apontam os depoimentos dos entrevistados Luiz Octávio de Lima Camargo e Mário Daminelli:

\footnotetext{
Mas aí voltei pro Brasil e daí o Requixa falou comigo... falou: escuta, você acha que o Dumazedier topa vir duas vezes por ano aqui pro Brasil, pra dar treinamento, pra ajudar o Sesc? E eu falei: ah, eu acho que topa (Luiz Octávio).

[...] foram reunidas todas as pessoas do corpo técnico, os animadores culturais que na época nem eram animadores culturais, eram orientadores sociais, e foram fazer uma grande reunião com o Dumazedier [...] (Mário Daminelli).
} 
Dumazedier liderou fóruns de discussões e seminários junto aos técnicos do CELAZER e de outros funcionários da entidade, e algumas vezes com a participação de convidados externos:

E havia às vezes pessoas convidadas de fora que interessavam né?, se interessavam. Principalmente acadêmicos, às vezes vinham participar. Porque o Dumazedier, na verdade ele foi contratado como uma espécie de orientador mesmo, do trabalho do Sesc. Então quando ele vinha pra São Paulo ele vinha com a incumbência de se dedicar a uma ação específica, que tivesse sendo desenvolvida aqui ou projetada enfim, imaginada. É... então ele vinha como um, digamos, um contratado para uma orientação do Sesc, dos funcionários, do corpo funcional do Sesc (Newton Cunha).

Bom, aí a gente estabeleceu junto com o Dumazedier uma rotina de trabalho no CELAZER, que envolvia treinamento interno, apoio teórico à programação, cursos externos e publicações (Luiz Octávio).

\section{E também na relação pessoal com Dumazedier residiram alguns dos aprendizados dos pesquisadores e colaboradores do CELAZER}

Ele tinha uma forma muito curiosa de escrever, ele ia produzindo vários textos ao mesmo tempo, no ambiente físico ocupado por ele, ele fazia uns nichos assim, tinha uma mesa que tinha uma porção de livros abertos, uma porção de folhas começadas, no outro canto uma outra mesinha com outra folha e outros livros, ele ia circulando, ele sentava num lugar escrevia um pouquinho e passava pro outro e escrevia o outro artigo, passava pro outro lugar preparava tal conferência, era metódico até nisso, ele trabalhava muito, ele trabalhava o tempo todo. Então o contato... não havia um contato muito amistoso, muito afável. Ele era meio durão, meio enérgico. Inclusive com quem estudou com ele né? Ele exigia muito mesmo, ele exigia uma produção escrita... Ele dizia que não era possível se formar um pesquisador sem que o pesquisador não produzisse de forma proporcional àquilo que ele consumia como informação. Eu não sei qual era o cálculo que ele fazia, mas eu acho que era: a cada dez páginas lidas tinha que ser produzida uma, era mais ou menos isso, a cada dez páginas que você lesse, você tinha a obrigação de produzir uma página. E esse resultado da leitura, ele dizia que tinha que ter três níveis: você tinha que fazer uma leitura... de cada texto você tinha que fazer uma leitura compreensiva e evidentemente entender o texto né?, em segundo lugar uma leitura crítica, ou seja, quais oposições você tem àquele texto e a terceira uma leitura criativa, ou seja, que ideias aquele texto te deu pro seu próprio trabalho, pra sua própria pesquisa. Então era muito interessante isso porque a gente de alguma forma se obrigava a fazer essas coisas e a abordagem de um texto era sempre... a abordagem do texto levando em conta essas três dimensões né?, o que eu compreendi disso, com o que que eu não concordo, porque que eu não concordo e no que que isso vai me ajudar no progresso do meu próprio questionamento intelectual (Dante Silvestre Neto).

É possível inferir, diante da leitura dos depoimentos e do contato com os entrevistados, que o mentor intelectual do CELAZER, além de compartilhar suas teorias e ensinamentos, promoveu certo encantamento também entre aqueles que tiveram a oportunidade de serem seus orientandos:

Foi tão sensacional que foi uma luz muito forte pra aqueles pequenos pesquisadores que eram pequenas velinhas acesas e se deixaram encantar por aquela luz muito, muito forte, uma presença fantástica e não só pela... uma presença muito forte não só pela acuidade intelectual dele, pela história de vida, Dumazedier tinha uma história de vida muito interessante. Ele veio de uma família muito pobre, a mãe era bordadeira, viúva, o pai morreu na primeira guerra mundial, ele... a formação dele foi devido a bolsas de estudos que ele recebia, bolsas governamentais. Na época da segunda guerra mundial ele pertenceu à resistência, atuou na resistência francesa, 
então tinha... isso nos atraia muito nele também, aquela biografia e aquele brilho (Dante Silvestre Neto).

Não há dúvidas de que a presença e a condução de Dumazedier foi fundamental para o desenvolvimento do quadro técnico da Instituição, bem como para a melhoria da ação institucional no campo do lazer no Brasil e projeção do Sesc na estruturação dos estudos do lazer no país:

E o Dumazedier trouxe essa importância dos estudos empíricos, que era importante também ter uma base, uma base concreta, uma base empírica a partir da qual você possa desenvolver as suas ideias e confrontá-las, e mesmo que você não concorde, ou desenvolver de forma diferente do que pensa a maioria mas, mas o/ele trouxe... uma contribuição muito grande na organização dessas ideias né? e principalmente na clarificação dos conceitos né?, conceitos operacionais, operacionais (Erivelto Garcia).

Passado todo esse tempo... eu acho que uma crítica poderia ser feita ao CELAZER, bom, uma modesta crítica, que é o seguinte: embora o Dumazedier fosse importante né?, talvez a gente devesse ter se dedicado também à produção de outros pesquisadores, pra confrontar maneiras de ver né? Mas na verdade o panorama era muito dominado por uma concepção de lazer que era puramente recreativa. Então havia os que achavam que... que misturavam o lazer com recreação, passatempo, e muita gente que achava que o lazer não era uma categoria sociológica, mas um dado mais psicológico, ou seja, considerava-se lazer aquilo que as pessoas gostavam, ou seja, se você trabalha e dentro do seu trabalho tem coisas agradáveis que você faz com satisfação, isso é também lazer...O velho Dumazedier detestava esse modo de pensar, ele achava que não. Que era um fato específico. E ele deu uma dimensão muito maior do que essa dimensão de recreação. Então ele, como é que ele falava?... os três Ds do lazer que era descanso, divertimento e desenvolvimento. E ele - e nós por tabela - dávamos muita importância a essa questão do desenvolvimento, até porque era, digamos assim, um compromisso institucional do Sesc, essa questão de promover a cultura das pessoas (Dante).

Essa parte dos conteúdos culturais é um dos grandes, das grandes definições que depois eu queria falar porque se você falar: o que o CELAZER deixou? Uma das coisas bem definidas é essa: é, quais são os conteúdos culturais do lazer. E o que que é conteúdo, o que que é interesse, que tem uma característica assim, antropológica também. Interesse não é só aquilo pelo qual alguém passa e olha, interesse é aquilo que vem de dentro da cultura né, isso é um interesse pro Dumazedier e nós chegamos a definir seis e que são aqueles utilizados hoje em dia ainda pelo Sesc, lógico subdivididos em centenas de atividades, mas os blocos são esses seis, que a gente pode falar depois (Luiz Octávio).

Deste modo, foi possível perceber como se deu a inserção das ideias de Dumazedier no Brasil. Embora não seja objeto deste texto, pressupomos que pelo alcance de sua ideias no SESC São Paulo e, posteriormente, pela influencia que estudiosos que estiveram com ele e que demonstraram potência acadêmica para influenciar outras gerações o fizeram, seu pensamento atravessou várias produções que marcadamente foram muito importantes para esta área e ainda reverberam, seja no sentindo de alicerçar a temática ou em diálogo, e serviram de suporte para alavancar críticas e mudanças conceituais.

Isto pode ser notado no depoimento a seguir:

Mas todos os nomes importantes do lazer hoje são egressos do Sesc. Eu, o Marcelino, o Bramante, o Pina, o Newton Cunha, quem mais? Dos mais antigos, dos avós, eu brinco, dos avós do lazer no Brasil, são todos egressos do Sesc né?, Se você 
for procurar um texto, como que é o nome dela, meu Deus do céu, é uma menina ${ }^{16}$ lá da UEL, da Universidade Estadual de Londrina, que fez uma, ela fez um estado da arte sobre o estudo do lazer no Brasil, ela termina no final dizendo o seguinte: a teoria do lazer é inteiramente herdada do Sesc (Luiz Octávio).

O texto a que se refere o Professor Luiz Octávio é o estudo de Peixoto e Pereira (2009), no qual as autoras afirmam:

A produção do conhecimento neste segundo ciclo vai ser impulsionada pelo CELAR (1973-1978, Porte Alegre) e pelo CELAZER/SESC de onde saem os autores que vão deflagrar a produção deste segundo ciclo e formar os quadros que serão responsáveis pelos terceiro e quarto ciclos da produção do conhecimento brasileira. [...] O Sesc, por sua vez, para além da atuação na prestação de serviços em lazer, também estruturou o CELAZER - Centro de Estudos do lazer e da Recreação (1979), [...] Volta-se principalmente para a formação do pessoal que atua nas várias unidades do Sesc espalhados pelo Brasil, mas suas produções são enviadas para as Bibliotecas [...] Alguns dos quadros formados pelo Serviço Social do Comércio virão, principalmente na década de 90, a participar da formação de profissionais graduados e pós-graduados pelas Universidades Brasileiras (PEIXOTO; PEREIRA, 2009, p. 9).

Da mesma forma, compreendemos e reafirmarmos a presença histórica e atual do pensamento de Dumazedier nos estudos do lazer no Brasil.

\section{CONSIDERAÇÕES FINAIS}

O CELAZER surgiu de um contexto político-institucional favorável ao aprofundamento das questões do lazer, motivado tanto pelo desejo pessoal da gestão da Instituição à época, quanto pelo próprio momento em que o país, em meio ao desenvolvimentismo propagado pelo governo militar, intensificava as preocupações sobre o lazer e os usos do tempo livre dos trabalhadores, com vistas a um direcionamento capaz de imprimir na população a ideia do uso adequado do tempo do não trabalho em benefício dos valores, da ordem, da recuperação física e da produtividade necessária ao desenvolvimento do país.

É possível apontar que além das pesquisas e publicações realizadas, o CELAZER contribuiu na constituição do pensamento sobre lazer no Brasil e na propagação do conhecimento adquirido nos seminários com Joffre Dumazedier. Contudo, como vimos, a presença de Dumazedier e seu pensamento sobre lazer no Brasil antecede o convite realizado por Renato Requixa e pelo Sesc.

Reafirmamos aqui, entretanto, que a força do pensamento de Dumazedier nos estudos do lazer no Brasil, sua clássica definição das funções do lazer pautadas nos três Ds: descanso, divertimento e desenvolvimento, e o desenvolvimento dos chamados Conteúdos Culturais do Lazer, foi disseminado no e pelo quadro técnico do Sesc São Paulo, por intermédio do CELAZER e, posteriormente, ampliado para as Universidades por meio dos técnicos e pesquisadores que deixaram o Sesc e seguiram suas carreiras acadêmicas. Isto aconteceu principalmente porque após o encerramento das atividades do CELAZER, muitos estudiosos migraram para importantes Universidades do estado de São Paulo e disseminaram, com isso, os conceitos e teorias estudados até então para outros espaços. 
O CELAZER esteve em atividade até 1983, enquanto Renato Requixa permaneceu como Diretor Regional do Sesc em São Paulo. Já o legado deixado por Dumazedier e seus estudos permanecem até hoje.

\section{REFERÊNCIAS}

ALMEIDA, M. B.; GUTIERREZ, G. L. Análise do desenvolvimento das práticas urbanas de lazer relacionadas à produção cultural no período nacional-desenvolvimentista à globalização. Revista Brasileira de Educação Física e Esporte, São Paulo, v. 25, n. 1, p. 137-52, jan./mar. 2011.

ARANHA, M. L. A. História da educação. São Paulo: Moderna, 1989.

BICKEL, M. C. P. O Serviço Social do Comércio e a produção de conhecimentos sobre o lazer no Brasil (década de 1970). 2013. 176 f. Dissertação (Mestrado Interdisciplinar em Estudos do Lazer) - Escola de Educação Física, Fisioterapia e Terapia Ocupacional, Universidade Federal de Minas Gerais, Belo Horizonte, 2013.

BRUNHS, H. T. (org.). Introdução aos estudos do lazer. Campinas: Editora UNICAMP, 1997.

CAMARGO, L. O. L. A pesquisa em lazer na década de 70. In: SEMINÁRIO O LAZER EM DEBATE, 4., 2003, Belo Horizonte. Anais [...]. Belo Horizonte: UFMG, 2003. p. 33-43.

DIAS, M. L. S. Ação, política e produção de conhecimento no campo do lazer: a experiência do Sesc São Paulo. In: SEMINÁRIO O LAZER EM DEBATE, 14., 2013, Campinas. Coletânea [...]. Campinas: SESC-UNICAMP, 2013. p. 32-40.

DUMAZEDIER, J. Questionamento teórico do lazer. São Paulo: SESC, 1975.

DUMAZEDIER, J. Lazer e cultura popular. São Paulo: Perspectiva, 1974.

GALANTE, R. C. Educação pelo lazer: a perspectiva do Programa Curumim do Sesc Araraquara. 2006. 141 p. Dissertação (Mestrado em Educação) - Centro de Educação e Ciências Humanas, Universidade Federal de São Carlos, São Carlos, 2006.

GHIRALDELLI JUNIOR, P. História da educação brasileira. São Paulo: Cortez, 2006.

GOMES, C. L. Lazer, trabalho e educação. 2. ed. rev. Belo Horizonte: Editora da UFMG, 2008.

GOMES, C. L. Projeto Garimpando Memórias. Porto Alegre: Centro de Memória do Esporte ESEF/UFRGS, 2004. Entrevista com Renato Requixa concedida a Christianne Gomes.

GOMES, C. L. Reflexões sobre os significados de recreação e de lazer no Brasil e emergência de estudos sobre o assunto (1926-1964). Conexões, Campinas, v. 1, n. 2, p. 1-14, 2003.

GOMES, C. L.; MELO, V. Lazer no Brasil: trajetória de estudos, possibilidades de pesquisa. Movimento, Porto Alegre, v.9, n. 1, p. 23-44, jan./abr. 2003.

GOMES, C. M. Dumazedier e os estudos do lazer no Brasil: breve trajetória histórica. In: SEMINÁRIO O LAZER EM DEBATE, 9., 2008, São Paulo. Anais [...]. São Paulo: EACH/USP-CELAR/UFMG, 2008. p. 1-12.

GONÇALVES JUNIOR, L. Lazer no período da ditadura militar: o desvelar de depoimentos de sindicalistas da Grande São Paulo - Brasil. Corpoconsciência, n. 10, p. 35-55, 2002.

JAMBEIRO, O.; MOTA, A.; RIBEIRO, A.; AMARAL, C.; SIMÕES, C.;COSTA, E.; BRITO, F.; FERREIRA, S.; SANTOS, S. Tempos de Vargas: o rádio e o controle da informação. Salvador: EDUFBA, 2004.

JOÃO, F.; CLEMENTE, E. História da PUC RS. Porto Alegre: EDIPUCRS, 1997. (volume 2). 
LANIADO, R. N. Poder e estratégias econômicas na formação do Estado autoritário no Brasil. In: GALLO, C. A.; RUBERT, S. (orgs.). Entre a memória e o esquecimento: estudos sobre os 50 anos do Golpe Civil-Militar no Brasil. Porto Alegre: Editora Deriva, 2014. p. 37-56.

MARCASSA, L. P. Movimentos e ideias sobre educação comunitária no Brasil: matrizes filosóficas e desdobramentos históricos no século XX. 2009. 313 p. Tese (Doutorado em Educação) - Faculdade de Educação, Universidade Estadual de Campinas, Campinas, 2009.

MARCASSA, L. P. A invenção do lazer: educação, cultura e tempo livre na cidade de São Paulo. 2002. 204 f. Dissertação (Mestrado em Educação Brasileira) - Faculdade de Educação, Universidade Federal de Goiás, Goiânia, 2002.

PEIXOTO, E.; PEREIRA, M. F. R. O segundo ciclo dos estudos do lazer no Brasil (1968-1979). In: SEMINÁRIO NACIONAL DE ESTUDOS E PESQUISAS: HISTÓRIA, SOCIEDADE E EDUCAÇÃO NO BRASIL, 8., 2009, Campinas. Anais [...]. Campinas: UNICAMP, 2009. p.1-23.

RODRIGUES, J. P. Uma nova versão sobre a história do Serviço de Recreação Operária: memórias reveladas sobre os anos de 1958 a 1964. 2010. 225 f. Tese (Doutorado em Educação) - Faculdade de Educação, Universidade de São Paulo, São Paulo, 2010.

SANT’ANNA, D. B. O prazer justificado: história e lazer. São Paulo: Marco Zero, 1994.

SESC SP. Século XXI. MAGALHÃES, H.; MARIN, P. R. (org.). Departamento Regional do Sesc São Paulo, 2013.

SESC SP. Os cinquenta anos do Sesc. Revista E, Publicação Periódica do Sesc São Paulo, v. 3, n. 3, p. 10-21, 1996.

SESC. Serviço Social do Comércio. Carta da Paz Social. 1. reimp. Rio de Janeiro: Sesc, fev. 2012. (publicação comemorativa).

SESC. Serviço Social do Comércio. Anais do $1^{\circ}$ Encontro Nacional sobre o lazer: cultura, recreação e educação física, 1975. Rio de Janeiro: Departamento Nacional, 1977.

SESC. Serviço Social do Comércio. Diretrizes gerais de ação do Sesc. Departamento Nacional, Rio de Janeiro, 1972.

WERNECK, C. Significados de recreação e lazer no Brasil: reflexões a partir da análise de experiências institucionais (1926-1964). 2003. 322 f. Tese (Doutorado em Educação) - Faculdade de Educação, Universidade Federal de Minas Gerais, Belo Horizonte, 2003.

Recebido em: 26 nov. 2021. Aprovado em: 21 jan. 2022. 